Research Paper:

\title{
Knowledge, Practice, and Attitude of Married Women crossuark About Preconception Care
}

Hamdia Mirkhan Ahmed $^{1 *}$, Tiran Jamil Piro

1. Department of Midwifery, College of Nursing, Hawler Medical University, Erbil, Iraq.

2. Department of Nursing, College of Nursing, Hawler Medical University, Erbil, Iraq.

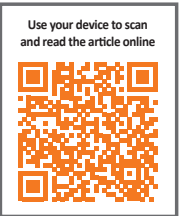

Crtation: Ahmed, M. H. \& Jamil Piro. T., 2017. Knowledge, Practice, and Attitude of Married Women About Preconception Care. Journal of Client-Centered Nursing Care, 3(1), pp. 37-44. https://doi.org/10.32598/jccnc.3.1.37

: https://doi.org/10.32598/jecnc.3.1.37

Article info:

Received: 10 Sep. 2016

Accepted: 30 Nov. 2016
Keywords:

Knowledge, Attitude, Practice, Women, Preconception care

\begin{abstract}
A B S T RA C T
Background: Preconception care is an organized and comprehensive program of health care that identifies and reduces woman's reproductive risks before conception through risk assessment, health promotion, and interventions. This study aimed to assess knowledge, practice, and attitude of married women about preconception care and find out the association between the level of knowledge and practice among them and some sociodemographic and obstetrical characteristics.

Methods: A descriptive study was conducted on 150 married women who had at least one pregnancy in Maternity Teaching Hospital in Hawler City and Taren primary health care center in Kasnazan from $26^{\text {th }}$ November 2015 to $10^{\text {th }}$ April 2016. The relevant data were collected through interview technique with study participants and filling out a questionnaire format, which contained five main parts: sociodemographic data, obstetric data, and knowledge, practice, and attitude of participants about preconception care. The obtained data were analyzed by using SPSS V. 22 through calculating frequencies and percentages and using Chi-square test.
\end{abstract}

Results: After collection of data and analyzing the study results, it was revealed that the highest percentage $(76.7 \%$ ) of mothers had fair knowledge, $20 \%$ poor knowledge, and $3.3 \%$ good knowledge about preconception care. The majority of the study sample $(68 \%)$ did not seek preconception care. Regarding attitude, $84.7 \%$ of the women had good attitude about preconception care.

Conclusion: Kurdish women need to be educated about the preconception care and it is an important duty by reproductive health care providers. Midwives can play vital role for improving preconception care concept among women.

\section{Background}

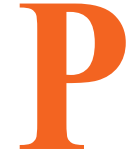

reconception care is defined as a set of interventions that aim to identify and modify biomedical, behavioral, and so- cial risks to the woman's health or pregnancy outcome through prevention and management. Certain steps should be taken before conception or early in pregnancy to maximize health outcomes (Johnson 2006). Preconception care is recognized as a critical component

\section{* Corresponding Author:}

Hamdia Mirkhan Ahmed, PhD

Address: Department of Midwifery, College of Nursing, Hawler Medical University, Erbil, Iraq.

Tel: +964 (750) 4478625

E-mail: hamdia76@gmail.com 
of health care for women of reproductive age. The main goal of preconception care is to provide health promotion, screening, and interventions for women of re- productive age to reduce risk factors that might affect future pregnancies. Preconception care is part of a larger health-care model that results in healthier women, infants, and families (Johnson 2006). Preconception period refers to a time span of anything from 3 months to 1 year before conception. But ideally it should include the time when both oocyte and sperm mature, which approximately 100 days before conception (Myles 1993).

The main components of preconception care are under four categories of interventions: maternal assessment (e.g. family history, behaviors, obstetric history, general physical exam), vaccinations (e.g. rubella, varicella, and hepatitis B), screening (e.g. HIV, STD, genetic disorders), and counseling (e.g. folic acid consumption, smoking and alcohol cessation, weight management) (Atrash et al. 2006). According to researchers' knowledge, no study has been done on preconception care in Kurdistan region so far. This study aimed to assess the level of knowledge, attitude, and practice of married women about preconception care and to find out the association between their level of knowledge, attitude, and practice and their sociodemographic and obstetrical characteristics.

\section{Materials \& Methods}

\section{Study design and participants}

A quantitative, descriptive design was used to assess the knowledge, practice, and attitude of married women about preconception care, from December 2015 to April 2016. Purposive sampling was used to select 150 married women with at least having the experience of one pregnancy, who attended Maternity Teaching Hospital and Taren primary health care centers in Kasnazan, Erbil City.

\section{Ethical consideration}

An official permission was obtained from Maternity Teaching Hospital and Taren primary health care center. Before collecting the data the oral consent was obtained from all study participants and purpose of the study was explained. The participants had right to withdraw from the study at any time.

\section{Data collection}

The relevant data were collected through interview technique with study participants and filling out a questionnaire format which contained five main parts: sociodemographic data, obstetrical data, as well as knowledge, practice, and attitude about preconception care.

Table 1. Sociodemographic data of the study sample

\begin{tabular}{ccc}
\hline Variables & & No. (\%) \\
\hline Age group, y & $<21(6.0)$ & $59(39.3)$ \\
& $21-31$ & $45(30.0)$ \\
& $31-40$ & $37(24.7)$ \\
\hline Level of education & $>40$ & $45(30.0)$ \\
& Illiterate & $64(42.7)$ \\
& Primary & $26(17.3)$ \\
Occupation & Secondary & $15(10.0)$ \\
& College \& higher & $127(85.2)$ \\
& Housewife & $22(14.8)$ \\
Religion & Employee & $149(99.3)$ \\
& Muslim & $1(0.7)$ \\
& Christian & $0(0.0)$
\end{tabular}




\section{Data analysis}

The obtained data were analyzed using SPSS V. 22, through calculating frequency and percentage and using the Chi-square test. The significance level was considered less than 0.05 .

\section{Results}

Table 1 presents that the highest percentage (47.3\%) of the mothers aged between $32-46$ years, $42.7 \%$ of mothers graduated from primary school, $85.2 \%$ were housewives, $99.3 \%$ were Muslim, and 51.3\% were living in suburban area. Table 2 presents that almost half of the mothers $(50.7 \%)$ were multigravida, $52 \%$ were multipara, $52 \%$ had no abortion, $82.7 \%$ did not have death baby, $66.7 \%$ had normal vaginal delivery in previous pregnancy, $96 \%$ had no congenital anomalies in their babies, $62.7 \%$ did not have complications in previous pregnancy, $66 \%$ had plan before their pregnancies. Sixty-eight percent of the study sample had experience of preconception care. Table 3 presents that the highest percentage of the mothers $(76.7 \%)$ had fair knowledge about preconception care, $20 \%$ poor knowledge, $3.3 \%$ good knowledge. About $84.7 \%$ of mothers had good attitude, $14.6 \%$ fair attitude and $0.7 \%$ poor attitude about preconception care. Among those (32\%) who had experience of preconception care, $64.6 \%$ had fair practice, $33.3 \%$ good practice and $2.1 \%$ poor practice. Majority of the study sample $(76.0 \%)$ have gained some knowledge about preconception care from their families or friends. The results of the present study show a significant association between occupation and abortion among the study sample with their level of

Table 2. Obstetrical data of the study sample

\begin{tabular}{|c|c|c|}
\hline & & No. (\%) \\
\hline \multirow{3}{*}{ Gravida } & Primigravida & $15(10.0)$ \\
\hline & Multigravida & $76(50.7)$ \\
\hline & Grand multigravida & $59(39.3)$ \\
\hline \multirow{3}{*}{ Para } & Primipara & $33(22.0)$ \\
\hline & Multipara & $78(52.0)$ \\
\hline & Grand multipara & $39(26.0)$ \\
\hline \multirow[b]{2}{*}{ Abortion } & No abortion & 799 (52.7) \\
\hline & With abortion & $71(47.3)$ \\
\hline \multirow{2}{*}{ Live birth } & Yes & $124(82.7)$ \\
\hline & No & $26(17.3)$ \\
\hline \multirow{3}{*}{ Method of delivery } & Normal delivery & $100(66.7)$ \\
\hline & Cesarian section & $28(18.7)$ \\
\hline & Both & $22(14.7)$ \\
\hline \multirow{2}{*}{ Fetal congenital anomalies } & No & $144(96.0)$ \\
\hline & Yes & $6(4.0)$ \\
\hline \multirow[b]{2}{*}{ Complications during pregnancy } & No & $94(62.7)$ \\
\hline & Yes & $56(37.3)$ \\
\hline \multirow{3}{*}{ Plan for pregnancy } & No & $36(24.0)$ \\
\hline & Yes & $99(66.0)$ \\
\hline & Sometimes & $15(10.0)$ \\
\hline \multirow{2}{*}{ Seeking preconception care in previous pregnancy } & Yes & 48 (32.9) \\
\hline & No & $102(68.0)$ \\
\hline
\end{tabular}


Table 3. Knowledge, practice and attitude of the study sample who had experience of preconception care $(n=48)$

\begin{tabular}{|c|c|c|c|}
\hline & \multicolumn{3}{|c|}{ Overall Levels } \\
\hline & Poor & Fair & Good \\
\hline & No. (\%) & No. (\%) & No. (\%) \\
\hline Knowledge & $30(20)$ & $115(76.7)$ & $5(3.3)$ \\
\hline Attitude & $1(0.7)$ & $22(14.6)$ & $127(84.7)$ \\
\hline Practice* & $1(2.1)$ & 31 (64.4) & $16(33.3)$ \\
\hline
\end{tabular}

knowledge about preconception care (Table 5), while there was no significant association between their sociodemographic and obstetrical characteristics and preconception care practice (Table 6). About 7.3\% and $24.0 \%$ of studied women had consulted with nurses/ midwives and obstetrician about preconception care, respectively. More than $40.0 \%$ of women used mass media to gain some knowledge. Also the results found significant association between sociodemographic and obstetrical characteristics of the study sample with experience of preconception care (Table 4).

\section{Discussion}

There has been increasing recognition that a woman's health statues, lifestyle, and her conception experiences

Table 4. Association between sociodemographic, obstetrical characteristics and having experience of preconception care

\begin{tabular}{|c|c|c|c|c|}
\hline & & No & Yes & \\
\hline & & No. (\%) & No. (\%) & \\
\hline \multirow{5}{*}{ Education } & Illiterate & 32 (71.1) & $13(28.9)$ & \multirow{5}{*}{0.730} \\
\hline & Primary & $45(70.3)$ & $19(29.7)$ & \\
\hline & & & & \\
\hline & Secondary & $16(61.5)$ & $10(38.5)$ & \\
\hline & College \& higher & $9(60.0)$ & $6(40)$ & \\
\hline \multirow{5}{*}{ Age group, $y$} & $<21$ & $7(77.8)$ & $2(22.2)$ & \multirow{5}{*}{0.028} \\
\hline & $21-30$ & $40(67.8)$ & $19(32.2)$ & \\
\hline & & & & \\
\hline & $31-40$ & $24(53.3)$ & $21(46.7)$ & \\
\hline & $>40$ & $31(83.8)$ & $6(16.2)$ & \\
\hline \multirow{3}{*}{ Residency } & Urban & $44(68.8)$ & $20(31.3)$ & \multirow{3}{*}{0.984} \\
\hline & Suburban & $52(67.5)$ & $25(32.5)$ & \\
\hline & Rural & $6(66.7)$ & $3(33.3)$ & \\
\hline \multirow{3}{*}{ Occupation } & Housewife & $87(68.5)$ & $40(31.5)$ & \multirow{3}{*}{0.652} \\
\hline & & & & \\
\hline & Employee & $14(63.6)$ & $8(36.4)$ & \\
\hline \multirow{3}{*}{ Parity } & Primi & $21(63.6)$ & $12(36.4)$ & \multirow{3}{*}{0.091} \\
\hline & Multi & $49(62.8)$ & $29(37.2)$ & \\
\hline & Grand multipara & $32(82.1)$ & 7 (17.9) & \\
\hline \multirow{3}{*}{ Gravida } & Primi & $12(80.0)$ & $3(20.0)$ & \multirow{3}{*}{0.062} \\
\hline & Multi & $45(59.2)$ & $31(40.8)$ & \\
\hline & Grand multigravida & $45(79.3)$ & $14(23.7)$ & \\
\hline
\end{tabular}


Table 5. Association between sociodemographic and obstetrical characteristics and the level of knowledge of the study sample about preconception care

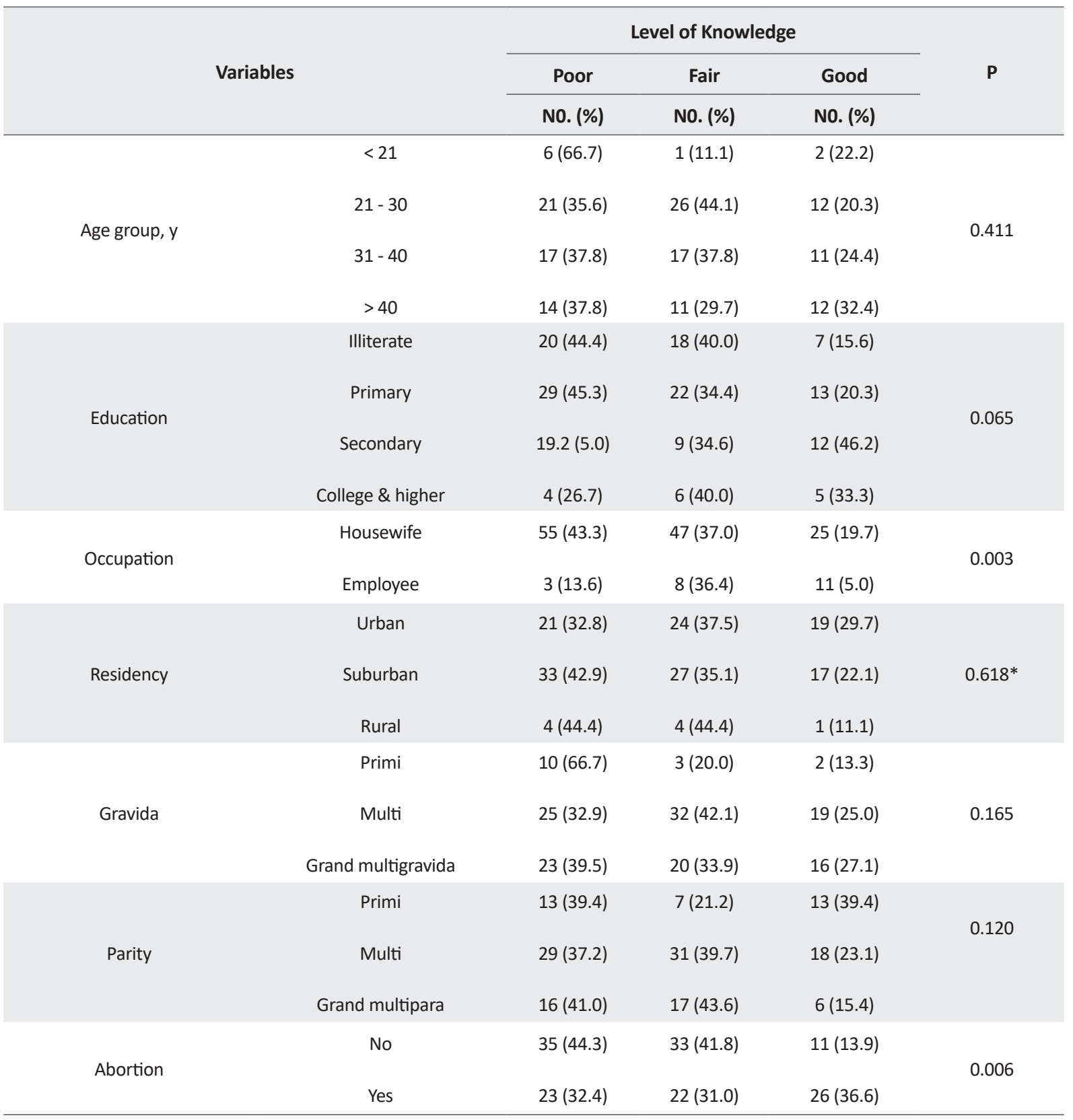

Client-Centered Nursing Care

strongly influence the achievement of a healthy pregnancy outcome (Myles 1993).

In the present study, the majority of the study sample had fair knowledge about preconception care. Nearly one quarter had poor knowledge about preconception care. Although most women had good attitude about preconception care, only $32 \%$ practiced it. In addition, the results of the present study showed statistically significant association between the level of knowledge of the women and their level of education, occupation, and experience about abortion. Also there is significant association between age and practicing preconception care.

The results emphasized that women who had previous negative obstetrical history were more interested in learning and practicing preconception care. The women with higher level of education had higher level of knowledge and practice. The result of the present study is similar to result of the study by Gautam and Dhakal (2016) on 227 reproductive age women. They assessed the women's knowledge about preconception care. Only 65 (28.63\%) 
Table 6. Association between sociodemographic, obstetrical characteristics and the level of practice of the study sample about preconception care

\begin{tabular}{|c|c|c|c|c|c|}
\hline & \multirow[b]{2}{*}{ Variables } & \multicolumn{3}{|c|}{ Level of Knowledge } & \multirow{3}{*}{$\mathbf{P}$} \\
\hline & & Poor & Fair & Good & \\
\hline & & NO. (\%) & NO. (\%) & NO. (\%) & \\
\hline \multirow{4}{*}{ Education } & Illiterate & $1(7.7)$ & $8(61.5)$ & $4(30.8)$ & \\
\hline & Primary & $0(0.0)$ & $12(63.2)$ & $7(36.8)$ & \multirow{3}{*}{$0.949 *$} \\
\hline & Secondary & $0(0.0)$ & $7(70.0)$ & $3(30.0)$ & \\
\hline & College \& higher & $0(0.0)$ & $4(66.7)$ & $2(33.3)$ & \\
\hline \multirow{2}{*}{ Occupation } & Housewife & $1(2.5)$ & $27(67.5)$ & $12(30.0)$ & \multirow{2}{*}{$0.514^{*}$} \\
\hline & Employee & $0(0.0)$ & $4(50.0)$ & $4(50.0)$ & \\
\hline \multirow{3}{*}{ Residency } & Urban & $0(0.0)$ & $12(60.0)$ & $8(40.0)$ & \multirow{3}{*}{0.744} \\
\hline & Suburban & $1(4.0)$ & $18(72.0)$ & $6(24.0)$ & \\
\hline & Rural & $0(0.0)$ & $1(33.3)$ & $2(66.7)$ & \\
\hline \multirow{3}{*}{ Gravida } & Primi & $0(0.0)$ & $2(66.7)$ & $1(33.3)$ & \multirow{3}{*}{0.852} \\
\hline & Multi & $1(32.0)$ & $21(67.7)$ & $9(29.0)$ & \\
\hline & Grand multigravida & $0(0.0)$ & $8(57.1)$ & $6(42.9)$ & \\
\hline \multirow{3}{*}{ Parity } & Primi & $0(0.0)$ & $9(75.0)$ & $3(25.0)$ & \multirow{3}{*}{0.608} \\
\hline & Multi & $1(3.4)$ & $19(65.5)$ & $9(31.0)$ & \\
\hline & Grand multipara & $0(0.0)$ & $3(42.9)$ & $4(57.1)$ & \\
\hline \multirow{2}{*}{ Abortion } & No & $1(4.8)$ & $15(71.4)$ & $5(23.8)$ & \multirow{2}{*}{$0.283^{*}$} \\
\hline & Yes & $0(0.0)$ & $16(59.0)$ & 11 (40.7) & \\
\hline
\end{tabular}

*Fisher exact test was applied.

had information about preconception care. Most respondents $(84.58 \%)$ had average level of knowledge. There was no association between sociodemographic characteristics of the women and their level of knowledge (Gautan \& Dhakal 2016). In a study in Oklahoma on 3749 women, to find out the rate of receiving preconception, $86.5 \%$ of women had not received preconception counseling or advice before becoming pregnant.

Those most likely to receive preconception counseling were 25-29 years of age, possessed some college education, had health insurance, had an intended pregnancy, and were married (Oklahoma State Department of Health 2008). According to the results of the present study, the health care providers play little role in giving necessary information about preconception care to mothers. The majority took information from the media. This may be due to policy of maternal and child health care in the Ministry of Health, which overlook preconception care and miss it as a routine care in primary health centers. Preconception advice is readily available in the mass media and the internet. However, the provision of preconception care is still not universal as the majority of services being provided by primary care practitioners, most of them opportunistic (Myles 1993). In a study of preconception services, Heyes (2004) found that while agreement upon the importance of preconception care was evident, factors that hindered the delivery of such provision were lack of training, recourses, and practice policies (Heyes 2004).

Kurdish women need to be educated about importance, benefits, and components of preconceptions care. Midwives and nurses can play significant role in improving the concept of preconception care. Health policy makers need to concentrate on this subject to promote healthy pregnancies.

\section{Acknowledgments}

This research did not receive any specific grant from funding agencies in the public, commercial, or not-for- 
profit sectors. Participation of two BSc midwives, Miss Roshna Khatab and Miss Ashna Abbas Hamad in this study as collector of data is appreciated.

\section{Conflict of Interest}

The authors declared no conflicts of interest.

\section{References}

Atrash, H. K., et al., 2006. Preconception care for improving perinatal outcomes: The time to act. Maternal and Child Health Journal, 10(1), pp. 3-11. PMCID: PMC1592246

Gautan, P. \& Dhakal, R., 2016. Knowledge on preconception care among reproductive age women. Saudi Journal of Medical and Pharmaceutical Sciences, 2(1), pp. 1-6.

Heyes, T., 2004. Preconception care: Practice and beliefs of primary care workers. Family Practice, 21(1), pp. 22-7. doi: 10.1093/fampra/cmh106

Johnson, K. et al., 2006. Recommendations to improve preconception health and health care-United States: A report of the CDC/ATSDR preconception care work group and the select panel on preconception care. Morbidity and Mortality Weekly Report, 55(6). doi: 10.1037/e506902006-001

Myles, M. F., 1993. Myles textbook for midwives. London: Churchill Livingstone.

Oklahoma State Department of Health., 2008. Preconception care among Oklahoma women. Oklahoma Pregnancy Risk Assessment Monitoring System, 12(1), pp. 1-6. doi: 10.1037/ e459272008-001. 
February 2017 . Volume 3. Number 1

Client-Centered Nursing Care

44 